\title{
Good practices in public procurement of engineering services
}

\author{
Alexis delos Reyes Darias
}

\begin{abstract}
:
This opinion articleoutlines the challenges involved when contracting engineering services by the Public Sector in Spain, and how they can be solved from a practical perspective
\end{abstract}

\section{Keywords:}

public procurement, engineering services, Spain.

\section{Introduction}

Contracting engineering services is a complex matter that requires a cautious and solid planning. technical, financial, economic, legal, organizational and experience aspects are involved and must be considered.

When procuring these services, the Spanish legislation contemplates option to use traditional procedures (open, negotiated or competitive dialogue), although it considers better suited the restricted procedure.

This is significant because until now the open or restricted procedures -widely used by any Administration, regardless of their size - had often been considered unsuitable for contracting complex and high-valueservices due to the problems derived from the costs, becausethey associate these procedures with a fixed price.

While the estimation of Open Book Costs, which is the negotiated procedure basis, came to solve that issue, it could also create possible conflicts of interest or violate the principles of equal treatment and transparency.

\section{The Spanish Public Procurement Law}

The Spanish Public Procurement Law (LCSP), in its Article 102.1, establishes that public sector contracts will always have a specified price, which will be paid to the contractor based on the services provided in accordance with the agreement, with a breakdown of prices except when this is not possible.

Therefore, the law establishes the need to determine a specified price that should not be confused with a fixed price, for which it will be necessary to save the asymmetry of economic information between contractors and contracting party.

The public purchase should not be low_cost, but neither should pay it at any price. It is about finding the best quality vs. price ratio by promoting conaurrence while leaving the door open to creative and innovative ideas.

Quality must be the key factor in theevaluation of theseservices. The LCSP itself establishes that the quality criteria should prevail and account for at least $51 \%$ of the assignable score in the valuation of offers (Article 145.4 of the LCSP). 
Engineering services are not commodities, and ther efore, the quality of these services can only be parameterized to certain limits, especially if we do not want to limit creativity and innovation. Additionally, the automation of theevaluation process, by means of formulas, does not necessarily produce objective results, since the formulas may be subject to bias and be reductionist, and they are, in fact, subject to controversy and dispute.

For the reasons stated, the objective evaluation of complex services requires to consider and evaluate specific and expert knowledge based on the criteria that have been previously defined.

The LCSP itself recognizes this when, even for therestrictive case of thesimplified open procedure, it allows the weighting of these criteria, based on value judgment, to reach $45 \%$ of the total score (Article 159.1.b).

A critical aspect of valuation methods is the use of value judgments and they require close attention. The LCSP itself establishes that, when its weighting is greater than the automatically evaluable criteria, the participation of an experts committee will be required (Article 146.2), establishing a clear separation between the roles of the body proposing the contract and the one evaluating the offers. This separation guarantees theindependence of thededision-making process of the Contracting Authority.

Therefore, there are three major challenges in this type of contract:

1) the asymmetry of economic information between contractors and contracting party.

2) the difficulty of promoting concurrence.

3) ensure the independence of the decision-making process of the Contracting Authority.

For the reasons stated, contracting authorities are increasingly relying on professional expertise to carry out complex and high-value public contracts, which is considered a good practice. The objective is the convergence of the principles and practices of good project management, contracts and cost auditing, ensuring the independence of the roles of the body proposing the contract and the one evaluating the offers.

The elaboration of technical requirements or the definition of the criteria for the evaluation of the offers, for both automatic and those that depend on valuejudgments, are theface of a coin in whose reverse resides the technical evaluation of the offers or the monitoring and control of contracted costs.

The identification of needs and solutions requires the participation of all interested parties in the process of defining the requirements and technical specifications of the contract.

The cost audit is the basis for the determination of budgets, of the eligible costs or for deciding risks al location between the Administration and the contractor.

Further to this, it may even be feasible to automatically reconcile the concepts of the electronic invoices with the details of the unit concepts accrued from the different data sources and in various formats (even unstructured), determining the admissible costs, that is, the costs of the services actually performed under the agreed terms and conditions, during the entire life cycle of the contract. 
For this to be feasible, the amounts of electronic invoice concepts must be disaggregated at the unit concept level defined in the spedifications but must be grouped into sets of technical and accounting elements that will allow us to verify that they are individually reasonable and acceptable by detecting, for example, if a contractor assigns expenses of a contract group to another, if the agreed conditions apply, if the number of units actually carried out are computed, etc.

\section{Conclusions}

We can recap and complete our recommendations for contracting engineering services by the Public Sector in the form of the following Decalogue:

1. I dentify and plan needs.

2. Involve all interested parties.

3. Use procurement procedures that are familiar with.

4. Define a true price in terms of unit prices.

5. Let the market propose creative and innovative solutions.

6. Search for the best quality / price ratio.

7. Separate the proposer and evaluator roles.

8. Deciderisk management and allocation.

9. Develop and implement a contract monitoring and evaluation plan.

10. Learn from experience.

\section{References}

- Ley 9/2017, de 8 de noviembre, de Contratos del Sector Público (LCSP). «BOE»núm. 272, de 09/11/2017. https://www.boe.es/eli/es///2017/11/08/9/con 